\title{
Silymarin Ameliorates Radiation Sickness and Weight Loss: An Experimental Study on Rodents
}

\author{
Sanam Ali, Farheen Shaikh, Kausar Abbas, Ayesha Iftikhar, Bashir Shaikh
}

\begin{abstract}
INTRODUCTION: lonizing radiation exposure may induce radiation sickness with critical weight loss. However, Silymarin administration showed to mitigate radiation induced weight loss and organ damage. OBJECTIVES: To evaluate the Histo-morphological changes in irradiated lungs, changes in body and absolute lung weight with protective effect of Silymarin.

METHODOLGY: This animal study was conducted in the Department of Anatomy, Basic Medical Sciences Institute, JPMC, Karachi during $1^{\text {st }}$ August 2015 to $31^{\text {st }}$ December 2015 after getting the approval from the Ethical Committee of BMSI, JPMC, Karachi. Fifty healthy adult male Wistar albino rats, divided into control group A, irradiated alone Group B and irradiated + Silymarin Group C were used. Group B and C were further divided into subgroups B1, B2 and C1, C2. Group B1 and C1, B2 and C2 received $13 \mathrm{~Gy}$ and $6 \mathrm{~Gy} \times 3 \mathrm{f}$ radiation respectively. Group $\mathrm{C} 1$ and $\mathrm{C} 2$ received Silymarin $(70 \mathrm{mg} / \mathrm{kg})$ orally additionally for 30 days.

RESULTS: Effect of Silymarin was assessed according to body weight and absolute weight of the lung. Statistical analysis of data of Group B showed significant decrease in body weight $(P<0.01)$ as compared with Group $A$, and a significant increase $(P<0.01)$ in the absolute weight of the lung compared to group A. Silymarin showed attenuating effect on weight loss $(P<0.01)$ and on lung weight $(P<0.01)$ in group $C$ as compared with group $B$.

CONCLUSION: Silymarin ameliorated radiation induced lung toxicity and improved weight loss. The protective effect may be contributed to Silymarins anti-oxidant and anti-inflammatory properties.
\end{abstract}

KEY WORDS: Ionizing radiation, Silymarin, Antioxidant, Anti-inflammatory, Reactive oxygen species.

This article may be cited as: Ali S, Shaikh F, Abbas K, Iftikhar A, Shaikh B. Silymarin Ameliorates Radiation Sickness and Weight Loss: An Experimental Study on Rodents. J Liaquat Uni Med Health Sci. 2017;16(04):222-7. doi: 10.22442/jlumhs.171640538

\section{INTRODUCTION}

For decades radiation therapy has been a mainstay of treating various neoplasms as adjuvant to surgery and chemotherapy ${ }^{1}$. Ionizing radiation (IR) exposure may lead to injury to normal tissues besides cancerous tissue. Radiation therapy to thorax is given in case of breast, lung, esophageal and lymphatic cancers. Normal tissue toxicity of lung, esophagus and cardiac muscle, is a common side effect of radiation therapy and a dose limiting factor ${ }^{2,3}$. Lungs, with little regenerative capacity are one of the most radiosensitive organs of the body 4 .

Radiation pneumonitis and fibrosis are two distinct clinical stages of radiation induced lung injury and contribute to major histopathological alterations in the normal cytoarchitecture of lung parenchyma. Acute inflammatory changes such as, alveolitis, influx of inflammatory cells and edema lead to increase in lung weight $^{5,6}$. A very common symptom during radiation therapy is critical weight loss, patients receiving radiation therapy frequently suffer from malnutrition, main cause being the loss of appetite, difficulty in swallowing and breathing, which cause reduce oral intake and leads to weight loss and morbidity ${ }^{7,8}$. Various experimental and clinical studies have revealed that there is an increased risk of critical weight loss and morbidity with high doses of radiation ${ }^{9}$.

The complex and well-established mechanism that causes the radiation sickness and radiation induced injury is the over production of free radicals ${ }^{10} .60-70 \%$ of cell damage caused by IR is attributed to free hydroxyl radicals $(\mathrm{OH})^{11}$. These reactive oxygen species (ROS) target biomolecules (DNA) and activate proinflammatory cells. Oxidative stress caused by ROS may induce various inflammatory cytokines, which initiates a molecular cascade that alters the surrounding microenvironment and leads to radiation induced tissue damage ${ }^{12}$. However, fortunately, oxidative stress caused by IR can be reversed by concomitant administration of antioxidants and radioprotectors ${ }^{13}$.

Radioprotection by Silymarin is a multifaceted phenomenon. Silymarin is extract of milk thistle seeds (silybum marianum) and contains flavonoglignans and 
flavonoids $^{14}$. For centuries Silymarin has been used as herbal medicine to treat hepatic diseases. Its beneficial effects have been attributed to its free radical scavenging, anti-inflammatory and antiproliferative (proapoptotic) activities, which represents the "functional triad" that is responsible for antagonizing the oxidative stress, thus preventing the organ damage. Silymarin has also been shown to have appetite stimulating effects ${ }^{15,16}$.

Silymarin has been effective in many drug-induced pulmonary and hepatic damage ${ }^{17,18}$. In this current study, we assessed the radioprotective activity of Silymarin following radiation on the basis of appetite, body weight, organ weight and histopathological changes.

\section{PURPOSE OF STUDY}

This study was conducted to observe the apparent feature, gross and histological changes in the irradiated lungs with radioprotective effects of Silymarin in Wistar albino rats.

\section{Objective of the study}

- To evaluate the Histo-morphological changes in irradiated lungs with protective effect of Silymarin.

- To evaluate the beneficial effects of Silymarin on radiation induced changes in body and absolute lung weight.

\section{Setting}

The study was conducted in the Department of Anatomy, Basic Medical Sciences Institute in collaboration with Atomic Energy Medical Centre, Jinnah Postgraduate Medical Centre, Karachi.

\section{Study Design}

Observational study on rodent model.

\section{Ethical Consideration}

Study was conducted after getting the approval from the Ethical Committee of BMSI, JPMC, Karachi.

\section{METHODS}

The experimental period was 30 days. Fifty Wistar Albino (Charles Broklyn Strain) rats were used from Animal House, BMSI. Animals were acclimatized in normal housing environment, with access to laboratory diet, water ad libitum. The rats were randomly divided into Groups A, B and C. Groups B and $C$ were further divided into subgroups $B 1, B 2$ and $C 1$ and C2 respectively and each group had 10 animals. Subgroups $B 1$ and $C 1$ received single dose of $13 \mathrm{~Gy}$ and subgroups B2 and C2 received 6GyX3f radiation to thorax respectively. Rats in subgroups $\mathrm{C} 1$ and $\mathrm{C} 2$ additionally received Silymarin $(70 \mathrm{mg} / \mathrm{kg}$ ) orally once a day. Animals were weighed weekly for monitoring body weight through the study period.

\section{Irradiation and Silymarin treatment}

Under general anesthesia with intraperitoneal injection of chloral hydrate $300-400 \mathrm{mg}$, correct positioning of the radiation fields of rat's thorax was achieved by using therapy simulator; X-rays were delivered by $6 \mathrm{mV}$ ONCOR LINAC (Siemen, Germany). Lungs, esophagus and mediastinum were irradiated. Silymarin was given in a dose of $70 \mathrm{mg} / \mathrm{kg}$ orally till the animals were euthanized. Silymarin was purchased from local pharmacy (Abbot Laboratories).

\section{Pathological Examination}

Animals were observed for apparent feature changes throughout the study period for appetite, body weight and hair loss. $30^{\text {th }}$ day post irradiation, rats were sacrificed. Lungs were dissected out and weighed. Tissue was fixed in $10 \%$ neutral buffered formalin for 24 hours, and processed as routine histological procedures. Paraffin embedded tissue blocks were made and sliced at $2 \mu \mathrm{m}$ thickness and stained with H\&E and Masson Trichrome. Histological assessment was performed under light microscope for alterations in the cytoarchitecture (Data not shown).

\section{Statistical Analysis}

Data was analyzed using SPSS version 19. Quantitative data was statistically analyzed using ANOVA with Tukey test for comparison of quantitative variables between groups. Results were presented as mean \pm standard deviation.

\section{RESULTS}

\section{Gross Pathology}

Lungs in control group were pink, soft and spongy in consistency, whereas in Group B, lungs were edematous with few hemorrhagic spots. Lungs in Group $C$ showed less edema as compared with Group B.

\section{Body weight and apparent feature changes GROUP A}

Rats in control group were active with good appetite and gained weight, mean value of initial and final body weight was $214 \pm 9.9$ and $22.3 \pm 10.1$ respectively (Table I and Bar chart I). The mean value of the absolute weight of the lung in control group was 1.38 \pm 0.14 (Table II and Bar chart III).

\section{GROUP B}

Rats in subgroup B1, were lethargic with retarded activities. Appetite was very poor. The weight loss was remarkable. Two animals died in $2^{\text {nd }}$ week. Initial and final body weight in subgroup B1, was $228 \pm 15.5$ and $168 \pm 10.1$ respectively (Table I and Bar chart I). The mean value of the absolute weight of the lung was $2.03 \pm 0.06$ (Table II and Bar chart II). In subgroup B2 animals were less lethargic, appetite was poor. All 
Sanam Ali, Farheen Shaikh, Kausar Abbas, Ayesha Iftikhar, Bashir Shaikh

animals survived. The weight loss was less remarkable as compared to subgroup B1. The initial and final body weight was $218 \pm 10.3$ and $164 \pm 14$ respectively (Table I and Bar chart I and II). The mean value of the absolute value of the lungs in subgroup B2 was $1.59 \pm 0.32$.

\section{GROUP C}

Animals in subgroup $\mathrm{C} 1$ and $\mathrm{C} 2$ were healthier and more active as compared with subgroup B1 and B2. Appetite was better and weight loss was mild. All animals survived. The mean value of initial and final body weight in subgroup C1 was $222 \pm 13.4$ and 215 \pm 12.7 respectively. The mean value of initial and final body weight in subgroup C2 was $217 \pm 8.7$ and 212 \pm 10.3 respectively. The mean value of the absolute weight of the lung in subgroup $\mathrm{C}$, was $1.45 \pm 0.17$ and $1.40 \pm 0.11$ respectively (Table I and II, Bar chart I, II and III). Data showed that the weight of the lung in Group C was decreased as compared with Group B. These observations show that Silymarin has beneficial effect on total body weight and over all inflammation of the organ.

\section{PERCENTAGE CHANGE (DECREASE) IN WEIGHT} FROM INITIAL BODY WEIGHT

\begin{tabular}{|l|c|}
\hline Groups & Average \% decrease \\
\hline Group B1 & 26.5 \\
\hline Group B2 & 24.6 \\
\hline Group C1 & 2.1 \\
\hline Group C2 & 2.6 \\
\hline
\end{tabular}

CHART I:

AVERAGE INITIAL BODY WEIGHT (GRAMS)

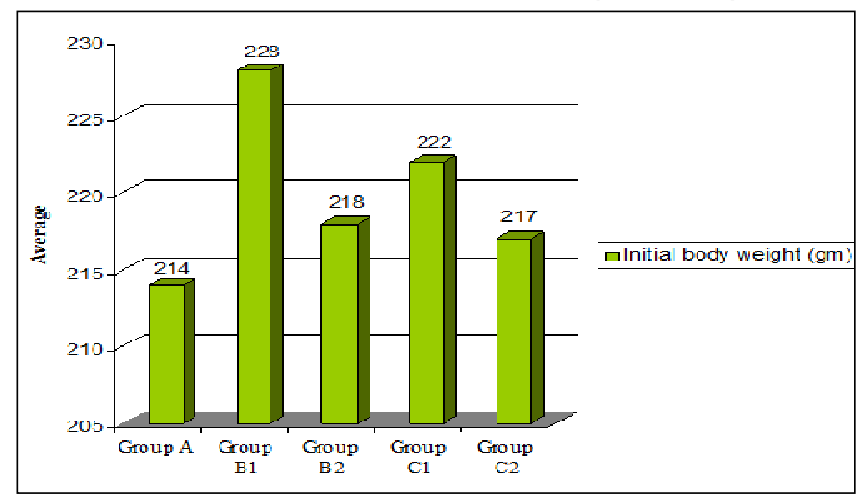

Significant difference was not observed in Initial body Weight in Group A, B1, B2, C1, C2 ( $p>0.05)$.

\section{CHART II:}

AVERAGE FINAL BODY WEIGHT (GRAMS)

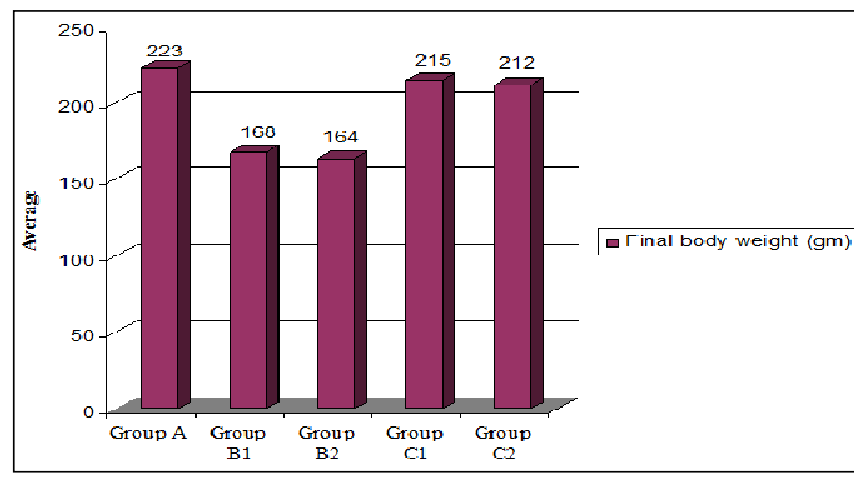

Final body weight was significantly decreased in Group B1, B2, as Compared to Group A (Controls) $(p<0.01)$

TABLE I: COMPARISON OF INITIAL AND FINAL BODY WEIGHT (GM) IN GROUPS A, B AND C

\begin{tabular}{|c|c|c|c|c|c|c|}
\hline & \multirow{3}{*}{$\begin{array}{c}\text { Group A } \\
(n=10)\end{array}$} & \multicolumn{2}{|c|}{ Group B } & \multicolumn{2}{|c|}{ Group C } & \multirow{3}{*}{$\begin{array}{c}P \\
\text { value }\end{array}$} \\
\hline & & $B 1(n=8)$ & B2 $(n=10)$ & $C 1(n=10)$ & C2 $(n=10)$ & \\
\hline & & SD & FD & SD+SL & FD+SL & \\
\hline Initial body Weight (gm) & $214 \pm 9.9$ & $228 \pm 15.5$ & $218 \pm 10.3$ & $222 \pm 13.4$ & $217 \pm 8.7$ & 0.101 \\
\hline Final body Weight (gm) & $223 \pm 10.1$ & $168 \pm 10.6$ & $164 \pm 14.3$ & $215 \pm 12.7$ & $212 \pm 10.3$ & 0.001 \\
\hline
\end{tabular}

Key: $S D=$ Single dose, $F D=$ Fractionated dose, $S L=$ Silymarin

TABLE II: COMPARISON OF ABSOLUTE WEIGHT (gm) AND RELATIVE WEIGHT OF LUNGS IN GROUPS A, B AND C

\begin{tabular}{|c|c|c|c|c|c|c|}
\hline & \multirow{3}{*}{$\begin{array}{c}\text { Group A } \\
(n=10)\end{array}$} & \multicolumn{2}{|c|}{ Group B } & \multicolumn{2}{|c|}{ Group C } & \multirow{3}{*}{$\begin{array}{c}P \\
\text { value }\end{array}$} \\
\hline & & $B 1(n=8)$ & $B 2(n=10)$ & $C 1(n=10)$ & $C 2(n=10)$ & \\
\hline & & SD & FD & SD+SL & $\mathrm{FD}+\mathrm{SL}$ & \\
\hline Absolute Weight of lungs (gm) & $1.38 \pm 0.14$ & $2.03 \pm 0.06$ & $1.59 \pm 0.32$ & $1.45 \pm 0.17$ & $1.40 \pm 0.11$ & 0.001 \\
\hline Relative Weight of lung & $0.61 \pm 0.06$ & $1.36 \pm 0.30$ & $0.97 \pm 0.23$ & $0.68 \pm 0.06$ & $0.66 \pm 0.04$ & 0.001 \\
\hline
\end{tabular}




\section{CHART III: ABSOLUTE WEIGHT (gm) OF LUNGS}

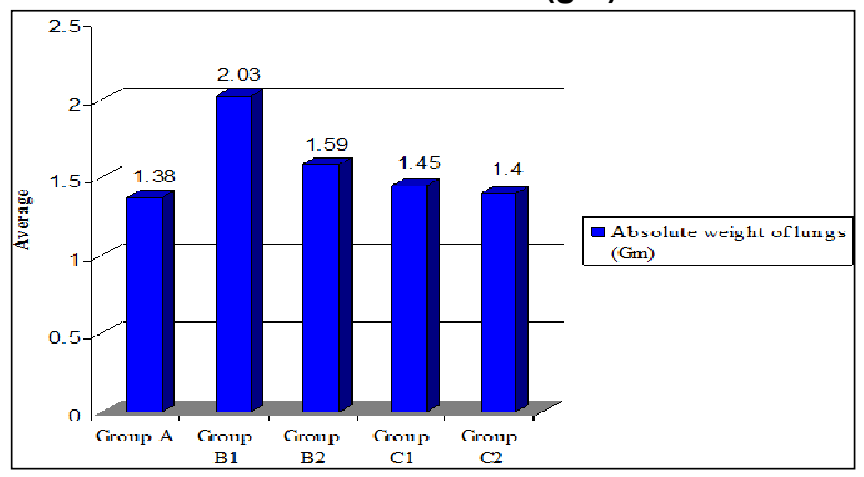

Weight of lungs were significantly high in Group $B 1$ as compared to $A, B 2, C 1, C 2(p<0.01)$

\section{FIGURE I: SIMULATION PROCESS BY USING INFRARED LIGHT}

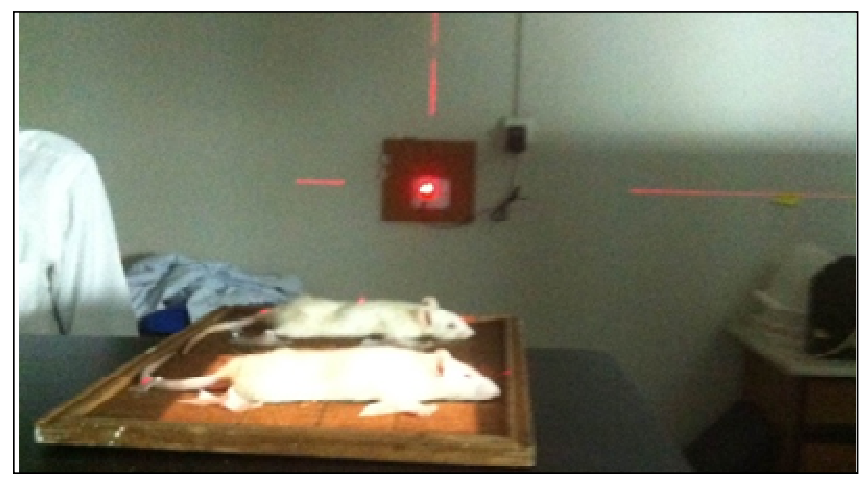

FIGURE II: FIELD SELECTION BY SIMULATION

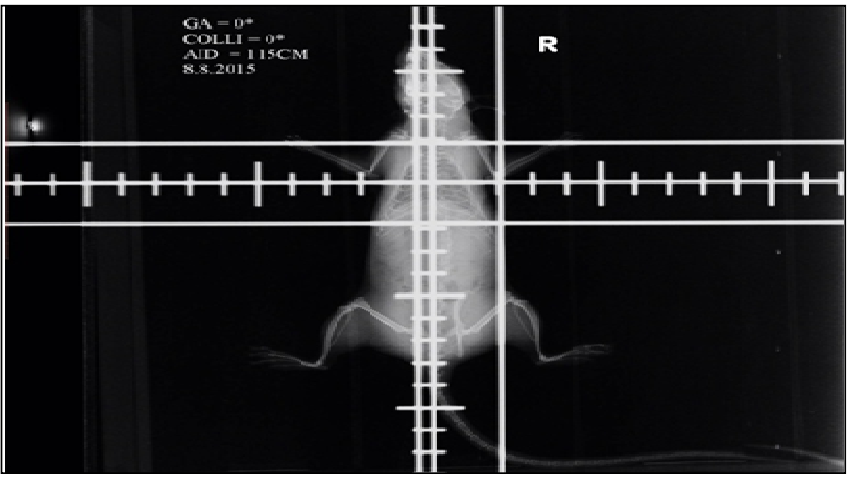

FIGURE III: GROSS MORPHOLOGY OF LUNGS

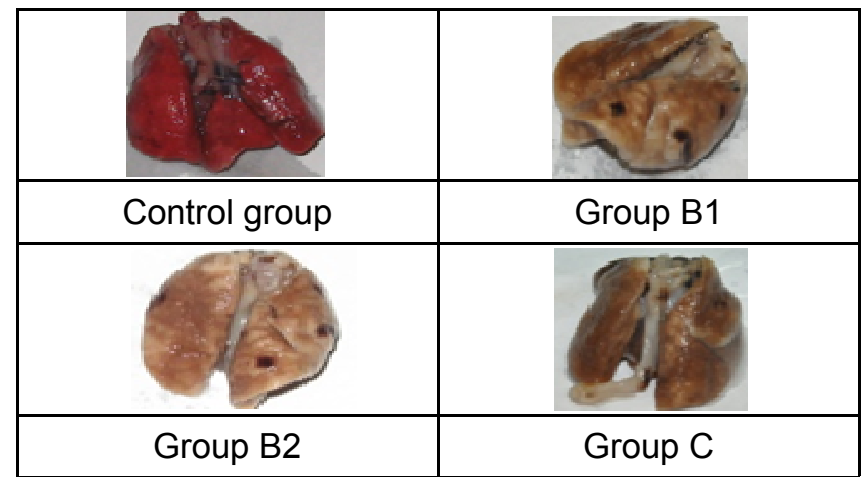

\section{DISCUSSION}

Normal tissue injury during radiotherapy is inevitable and often if not always, a dose limiting factor. Radiation to thorax for lung, breast, esophageal and lymphatic cancer can also damage normal tissue as well. The soft tissue injury to esophagus can cause dysphagia and nausea which can limit the oral intake ${ }^{3}$. Malnutrition is a frequent occurrence in patients receiving radiotherapy and may cause a wide range of superimposed adverse events ${ }^{7}$.

The present study was designed to observe the protective effect of Silymarin at gross and histological level on irradiation induced toxicity in rats. The primary aim of the study was to study the effect of single high dose and small fractionated doses of X-rays on appetite, body weight and absolute weight of the lungs. In our study animals treated with radiation alone were lethargic and inactive with poor intake of food. Severe weight loss was observed; however, weight loss was less severe in animals that received small fractionated doses of radiation (Group B2). It is noteworthy that animals that received Silymarin + radiation showed improved level of activity, good food intake and hence less weight loss. Radiation induced weight loss is attributed to radiation sickness. lonizing radiations lead to over production of ROS, which in turn induce the inflammatory changes in the esophagus and cause acute dysphagia and poor appetite. These changes are dose, dose volume and fractionation of dose dependent ${ }^{3}$. Radiation-induced dysphagia is a prominent cause of critical weight loss $^{10}$. Consistent with our results, the mean weight loss in our experimental animals (Group B) was $25 \%$. Critical loss during radiation therapy is correlated with reduction of treatment tolerance, increased risk of infection and early mortality ${ }^{8}$. Al-Enazi et $\mathrm{al}^{19}$ reported in their work that Silymarin has anti-inflammatory and antioxidative properties and has beneficial effects on weight loss and organ weight changes; a finding which is in agreement to the results of current study. Gyengesi $\mathrm{E}$ et al ${ }^{20}$, reported that oxidative stress can affect hypothalamic neurons and is responsible for the central mechanism of poor appetite. Silymarin is considered an appetite stimulant due to its strong antioxidative properties ${ }^{16,19}$. It is worth paying attention to that keeping the weight loss at minimum can improve the quality of life in patients receiving radiation therapy ${ }^{7}$. Another aspect of current study was the decrease in the absolute weight of the lungs in animals that received Silymarin + radiation.

Wahlstrom $\mathrm{E}$ et $\mathrm{al}^{21}$ have reported in their study that organ weight has been accepted as a valuable parameter in toxicological studies and that lung weight 
changes were often associated with lung histopathology. Radiation induced inflammation of the lungs with edema contribute to increased lung weight and Silymarin can down regulate the inflammation, and hence the absolute weight of the lungs ${ }^{17}$.

\section{CONCLUSION}

lonizing radiation can cause acute radiation sickness, poor appetite and critical weight loss and Silymarin administration can ameliorate radiation induced toxicity and prevent weight loss.

\section{REFERENCES}

1. Ding $\mathrm{NH}, \mathrm{Li} \mathrm{JJ}$ and Sun LQ. Molecular mechanisms and treatment of radiation induced lung fibrosis. Curr Drug Targets. 2013; 14 (11):1347-56.

2. Arguder E, Yildirim BA, Hasanoglu HC. Pulmonary toxicities and treatment of radiation therapy. Eurasian J Pulmonol. 2014; 16:150-8.

3. Fountain MD, Abernathy LM, Lonardo $F$, Rothstein SE, Dominello MM, Yunker CK, et al. Radiation induced esophagitis is mitigated by soy isoflavones. Frontiers Oncol. 2015; 5:238. doi: 10.3389/fonc.2015.00238.

4. Tabarraei Y, Bakhshandeh Z, Behrouzkia Z, Peirouvi T, Pourissa M, Asghari M, et al. Short term changes in histopathological markers of irradiated rat's lung: preliminary study. Res J Pharmaceu Biol Chem Sci. 2014; 5(3):307-315

5. Porter DW, Hubbs AF, Mercer R, Robinson VA, Ramsey D, Mclaurin J, et al. Progression of lung inflammation and damage in rats after cessation of silica inhalation. Toxicol Sci. 2004; 79(2):370380.

6. Li H, Wu H, Gao Y and Cai S. Effect of Yangyinquingfei decoction on radiation induced lung injury via downregulation of MMP12 and TIMP-1 expression. Exp Ther Med 2014; 8(1):9-14. doi: 10.3892/etm.2014.1686

7. Cacicedo J, Casquero $F$, Martinez-Indart $L$, del Hoyo O, de iturriaga AG, Navarro A and Bilbao P. A prospective analysis of factors that influence weight loss in patients undergoing radiotherapy. Chinese J Cancer. 2014; 33(4):204-210.

8. Li G, Jiang X, Qiu B, Shen L, Chen C and Xia Y. Vicious circle of acute radiation toxicities and weight loss predicts poor prognosis for nasopharyngeal carcinoma patients receiving intensity modulated radiotherapy. J Cancer. 2017; 8(5):832-838. doi: 10.7150/jca.17458

9. Qibin S, Weiguo H, Yuxin C, Xubin, Hao C. Establishment of a rat model of radiation induced lung injury. Intern J Radiat Res. 2014; 12(3):223227.

10. Langius JAE, Bakker S, Rietveld DHF, Kruizenga HM, Langendijk JA, Weijs PJM, et al. Critical weight loss is a major prognostic indicator for disease specific survival in patients with head and neck cancer receiving radiotherapy. $\mathrm{Br} \mathrm{J}$ Cancer 2013; 109(5):1093-1099. doi: 10.1038/ bjc. 2013.458

11. Azzam El, Jay-Gerin JP, Pain D. Ionizing radiation induced metabolic oxidative stress and prolonged cell injury. Cancer Lett. 2012; 327(1-2):48-60. doi: 10.1016/j.canlet.2011.12.012.

12. Han X, Xue X, Zhao Y, Li Y, Liu W, Zhang J, et al. Rutin enriched extract from Coriandrum sativum L. Ameliorates ionizing radiation induced hematopoietic injury. Intern J Mol Sci. 2017; 18(5): pii: E942. doi: 10.3390/ijms18050942.

13. Arora R, Adhikari M, Agarwal P, Chawla R, Gupta $\mathrm{D}$, Sharma RK, et al. Amelioration of g-radiation induced genotoxicity by nanosilymarin: A comparative study indicates possible implications for chemical biological radiological and nuclear (CBRN) defence. Trakia J Sci. 2014; 12(Suppl. 1):1-10.

14. Federico A, Dallio M and Loguercio C. Silymarin/ Silybin and chronic liver disease: A marriage of many years. Molecules, 2017; 22(2): pp: E191. doi: 10.3390/molecules22020191.

15. Nabavi SM, Nabavi SF, Moghaddam AH, Setzer WN, Mirzaei M. Effect of silymarin on sodium fluoride induced toxicity and oxidative stress in rat cardiac tissues. An Acad Bras Cienc. 2012; 84 (4):1121-1126.

16. Jahan S, Khan $M$, Imran $S$, Sair $M$. The hepatoprotective role of silymarin in isoniazid induced liver damage of rabbits. J Pak Med Assoc. 2015; 65(6):620-2.

17. Azarkhiavi RK, Ali-Omrani M, Solgi R, Bagheri $P$, Haji-Noormohammadi $M$, Amani $N$, et al. Silymarin alleviates bleomycin-induced pulmonary toxicity and lipid peroxidation in mice. Pharm Biol. 2014; 52(10):1267-71.

18. Kalemci S, Topal Y, Celik SY, Yilmaz N, Beydilli $\mathrm{H}$, Kosar MI, et al. Silibinin attenuates methotrexate induced pulmonary injury by targeting oxidative stress. Exp Ther Med. 2015; 10(2): 503-7. doi: 10.3892/etm.2015.2542

19. Al-Enazi MM. Combined therapy of rutin and silymarin has more protective effects on streptozotocin induced oxidative stress in rats. $\mathrm{J}$ Appl Pharmacol Sci. 2014; 4(1):021-028.

20. Gyengesi E, Paxinos G, Andrews ZB. Oxidative 
stress in the hypothalamus: the importance of calcium signaling and mitochondrial ROS in body weight regulation. Curr Neuropharmacol. 2012; 10 (4):344-353. doi: 10.2174/157015912804143496
21. Wahlstrom E, Ollerstam A, Sundius L, Zhang $H$. Use of lung weight as biomarker for assessment of lung toxicity in rat inhalation studies. Toxicol Pathol. 2013; 41(3):902-912.

AUTHOR AFFILIATION:

Dr. Sanam Ali

Assistant Professor, Department of Anatomy

BMSI, JPMC, Karachi, Sindh-Pakistan.

Dr. Farheen Shaikh (Corresponding Author) Assistant Professor, Department of Biochemistry LUMHS, Jamshoro, Sindh-Pakistan.

Email: shaikhfarheen14@gmail.com

Dr. Kausar Abbas

Assistant Professor, Department of Physiology BMSI, JPMC, Karachi, Sindh-Pakistan.

Dr. Ayesha Iftikhar

Assistant Professor, Department of Pathology

BMSI, JPMC, Karachi, Sindh-Pakistan.

Dr. Bashir Shaikh

Assistant Professor, Department of Anatomy

SMBBMC Lyari, Karachi, Sindh-Pakistan. 